\title{
Tiroiditis aguda supurada en una paciente con fístula del seno piriforme: presentación de un caso
} Acute suppurative thyroiditis in a patient with a piriform sinus fistula: A case report

\author{
Dra. María F. Courtois ${ }^{a}$ Dr. Nicolás F. Colom ${ }^{a}$, Dra. María A. Rodas ${ }^{a}$, Dra. Vanina Magnanelli ${ }^{a}$ \\ Dra. Florencia Palmieri ${ }^{a}$ Dra. Lorena Mirón ${ }^{a}$ y Dra. Beatriz Muracciole ${ }^{a}$
}

\section{RESUMEN}

La tiroiditis aguda supurada es una entidad poco frecuente en pediatría; de origen infeccioso, cuya etiología más frecuente es bacteriana. Su presentación típica en niños es la aparición de una tumoración en la cara anterior del cuello, con signos de flogosis, dolorosa, caliente y eritematosa, que excursiona con la deglución, y puede o no estar acompañada de fiebre, disfagia o disfonía.

En niños, las anomalías congénitas, principalmente la fístula del seno piriforme, predisponen a la infección de la glándula, por lo quees importantela resolución quirúrgica del defecto anatómico para prevenir las recurrencias. El diagnóstico rápido, basado en la clínica y los estudios por imágenes, es importante para comenzar en forma temprana con un tratamiento antibiótico adecuado.

Se presenta una paciente de 3 años, previamente sana, con tumoración cervical izquierda dolorosa y asociada a fiebre. Durante la internación, se arribó al diagnóstico de tiroiditis aguda supurada secundaria a fístula de seno piriforme.

Palabras clave: tiroiditis, niño, fístula, seno piriforme.

\begin{abstract}
Acute suppurative thyroiditis is an infectious disease, uncommon in children, caused by various microorganisms, being bacteria the most frequently involved. The typical presentation includes the appearance of a tumor in combination with signs of swelling in the anterior aspect of the neck, which is painful on palpation and is associated with warmth and erythema. It usually moves with swallowing and the patient can suffer fever, dysphagia or dhysfonia.

In children, congenital anomalies can lead to the gland's infection, and the surgical excision of them is important to prevent recurrency. A quick diagnosis, based on clinical manifestations and imaging studies, is necessary to install an adequate antibiotic treatment.

We present the case of a 3-year-old patient, who was previously healthy, with a painful left cervical tumor associated with fever.
\end{abstract}

a. Unidad 6 de Clínica Pediátrica, Hospital de Niños Ricardo Gutiérrez, Ciudad Autónoma de Buenos Aires, Argentina.

\section{Correspondencia:}

Dra. Florencia Palmieri: flor.palmieri@gmail.com

Financiamiento: Ninguno.

Conflicto de intereses: Ninguno que declarar.

Recibido: 6-11-2020

Aceptado: 23-3-2021
During the hospitalization, we reached the diagnosis of acute suppurative thyroiditis caused by an underlying pyriform sinus fistula.

Key words: thyroiditis, child, fistula, pyriform sinus.

http: / / dx.doi.org/10.5546/aap.2021.e518

Cómo citar: Courtois MF, Colom NF, Rodas MA, Magnanelli V, et al. Tiroiditis aguda supurada en una paciente con fístula del seno piriforme: presentación de un caso. Arch Argent Pediatr 2021;119(5):e518-e521.

\section{INTRODUCCIÓN}

La tiroiditis aguda supurada (TAS) es infrecuente en pediatría, y se la considera una emergencia endocrinológica por su potencial gravedad. Su incidencia varía entre el 0,1 \% y el $0,7 \%$ de todas las enfermedades tiroideas. ${ }^{1}$ $\mathrm{Su}$ origen infeccioso es causado principalmente por agentes bacterianos. Suele presentarse como una tumoración cervical, duro-elástica, dolorosa, eritematosa y con aumento de la temperatura local. También puede manifestarse con fiebre, disfagia y, con menor frecuencia, disfonía. ${ }^{2}$ En los niños, el lóbulo izquierdo es el más afectado, lo que podría reflejar la presencia de un trayecto fistuloso congénito desde el seno piriforme hasta la glándula, ${ }^{3}$ por lo que todos los pacientes deberían ser estudiados para identificar la presencia de dicha condición.

\section{CASO CLÍNICO}

Paciente de sexo femenino de 3 años y 5 meses de edad, previamente sana, cuyos padres consultan por dolor y tumoración en región cervical izquierda de 48 horas de evolución asociado a único registro febril de $38,2^{\circ} \mathrm{C}$. Dos semanas antes de la consulta presentó antecedente de faringoamigdalitis tratada en forma empírica con amoxicilina por 10 días, sin realización previa de hisopado de fauces.

Durante la consulta se realizó una ecografía de la región cervical donde se observó la glándula tiroides de tamaño adecuado, con alteración difusa de la ecoestructura del lóbulo izquierdo 
y zonas hiperecoicas e hipoecoicas (compatibles con un absceso) con contenido aéreo y solución de continuidad de 3,5 $\mathrm{mm}$ en planos profundos de trayecto fistuloso hacia la vía aérea superior (Figura 1).

Al ingresar, se la evalúa en buen estado general y eutrófica. La tumoración duroelástica en la región lateral izquierda del cuello compromete desde la región posterior del músculo esternocleidomastoideo hacia la línea media, con áreas eritematosas y aumento de la temperatura local, sin zonas de reblandecimiento y dolorosa a la palpación superficial (Figura 2).

Los estudios de laboratorio realizados inicialmente fueron normales, a excepción de un aumento de la proteína $C$ reactiva $(P C R)$ con un valor de 70,6 mg/l, e incluyeron una evaluación hematológica con leucocitos de $13200 / \mathrm{mm}^{3}$, hemoglobina de $10,8 \mathrm{~g} / \mathrm{dl}$ y plaquetas de 470000 / $\mathrm{mm}^{3} \mathrm{y}$ parámetros función renal y hepática. Además, se realizó un perfil tiroideo dentro de límites normales y un par de hemocultivos con resultado negativo.

Para ampliar los estudios diagnósticos, se realizó tomografía axial computada (TAC) de cuello y tórax con contraste, en la cual se observó una masa con densidad de partes blandas en la base del cuello del lado izquierdo en contacto con la glándula tiroides y en el espesor del músculo esternocleidomastoideo, con compromiso predominante del tercio distal de este músculo. La imagen presenta un refuerzo heterogéneo luego de la administración de contraste intravenoso (IV) y un diámetro aproximado de $3,5 \mathrm{~cm}$; se determina que puede corresponder a un absceso (Figura 3).

Debido a la consistencia duro-elástica de la tumoración, se decidió no realizar una toma de muestra por medio de punción aspiración con aguja fina, y se inició tratamiento antibiótico por vía IV con clindamicina, y fomentos.

La paciente evolucionó favorablemente durante la internación, afebril, con buena respuesta al manejo del dolor y disminución del tamaño de la tumoración. Recibió 14 días de antibioticoterapia por vía IV con clindamicina; luego se rotó a la vía oral con amoxicilina-ácido clavulánico y trimetoprima sulfametoxazol durante 23 días totales hasta la resolución completa de la lesión.

En cuanto a la fístula del seno piriforme, se realizará la corrección quirúrgica de forma diferida.

\section{DISCUSIÓN}

La TAS es una condición infrecuente en la población infantil, incluso en pacientes inmunocomprometidos, pero que debe considerarse una emergencia debido al dolor y el estado tóxico que podría producir en el niño. ${ }^{4} \mathrm{Se}$ trata de una infección de instalación hiperaguda, ${ }^{5}$ causada por diversos microorganismos, de los cuales las bacterias son los más frecuentes. Las bacterias grampositivas, en especial el Staphylococcus aureus y, en menor medida, el Streptococcus pyogenes y el S. pneumoniae, son los causantes más comunes, tanto en niños como en adultos. Le siguen en frecuencia Haemophilus

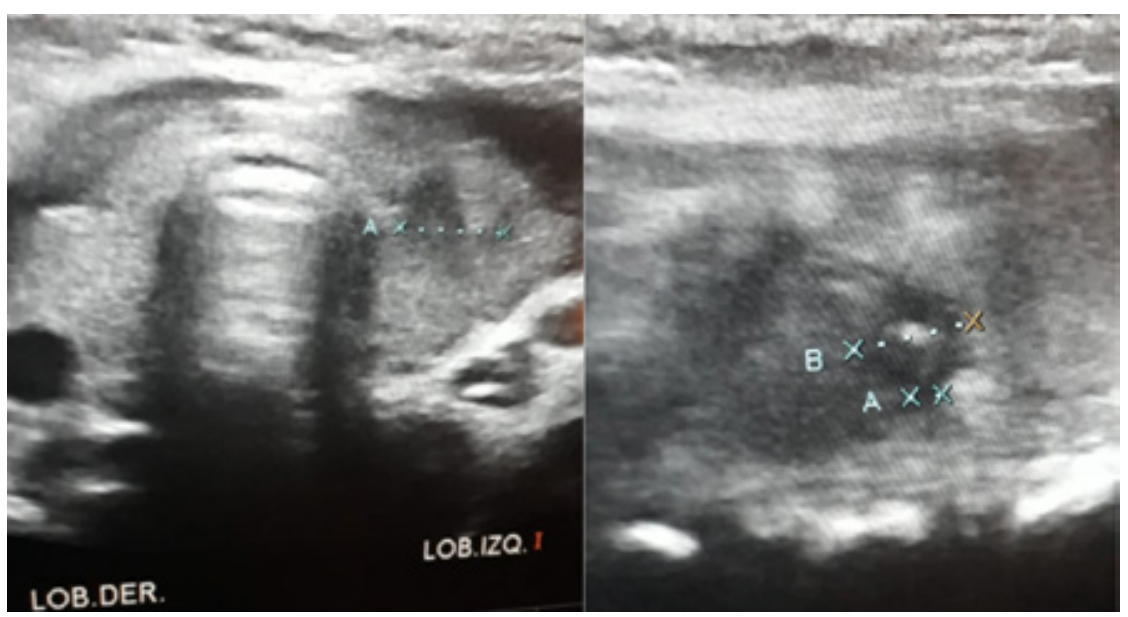

Se observa lóbulo izquierdo con áreas hiperecogénicas e hipoecogénicas y solución de continuidad de 3,5 mm en planos profundos de trayecto fistuloso hacia la vía aérea superior. 
influenza, Klebsiella spp. y Salmonella spp., y algunos microorganismos anaerobios (Bacteroides spp. y Fusobacterium). Sin embargo, se han notificado casos producidos por hongos, parásitos y virus. ${ }^{3}$

Su diseminación puede producirse por vía hemática, linfática o por continuidad. Diferentes anomalías congénitas, como la persistencia del conducto tirogloso o la fístula de seno piriforme,

FIGURA 2. Tumoración cervical duro-elástica, con aumento de la temperatura local y eritema

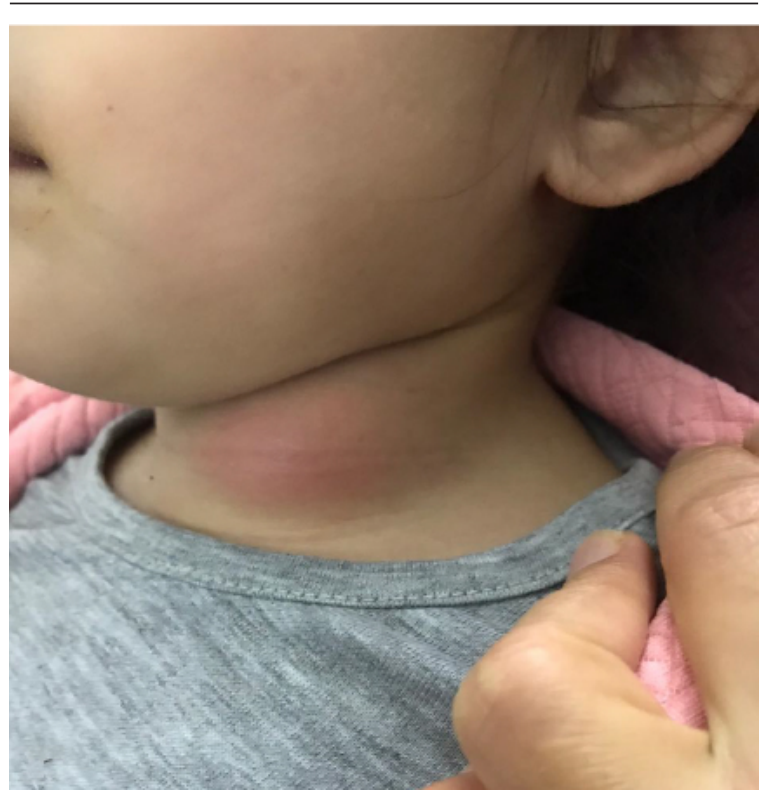

vestigio embriológico del $3^{\circ}$ o $4^{\circ}$ arco branquial, proveen una comunicación directa para la llegada de microorganismos causantes de la TAS. ${ }^{3}$ En niños, la mayoría de los casos son secundarios a este tipo de malformaciones, que fue la principal sospecha diagnóstica en la paciente aquí presentada.

Las fístulas del seno piriforme, situado en la hipofaringe, se extienden desde este hasta la glándula tiroidea o el espacio peritiroideo. Se pueden originar en la base o el ápice del seno, según provengan del $3^{\circ} \mathrm{o} 4^{\circ}$ arco, y en su trayecto se relacionan con los nervios glosofaríngeo, laríngeo superior y recurrente. ${ }^{6}$ El defecto anatómico puede visualizarse de manera directa por laringoscopia o mediante otros exámenes complementarios como el esofagograma con bario o la TAC, con un rédito de detección del $100 \%, 50 \%$ y $80 \%$, respectivamente. ${ }^{1}$ Diversos autores concuerdan en que estos estudios deben realizarse de 4 a 6 semanas luego de resuelto el proceso infeccioso agudo ya que, durante este, el trayecto podría estar ocupado por material inflamatorio que impide su correcta identificación. Particularmente en el caso mencionado, al haberse identificado el trayecto fistuloso por ecografía, no fue necesario realizar otro estudio contrastado para evidenciarlo. No se visualizó el trayecto fistuloso en la TAC, aunque es probable que se deba a que dicho estudio se realizó durante el período agudo.

FIGURA 3. Tomografía axial computada de la región cervical, corte axial

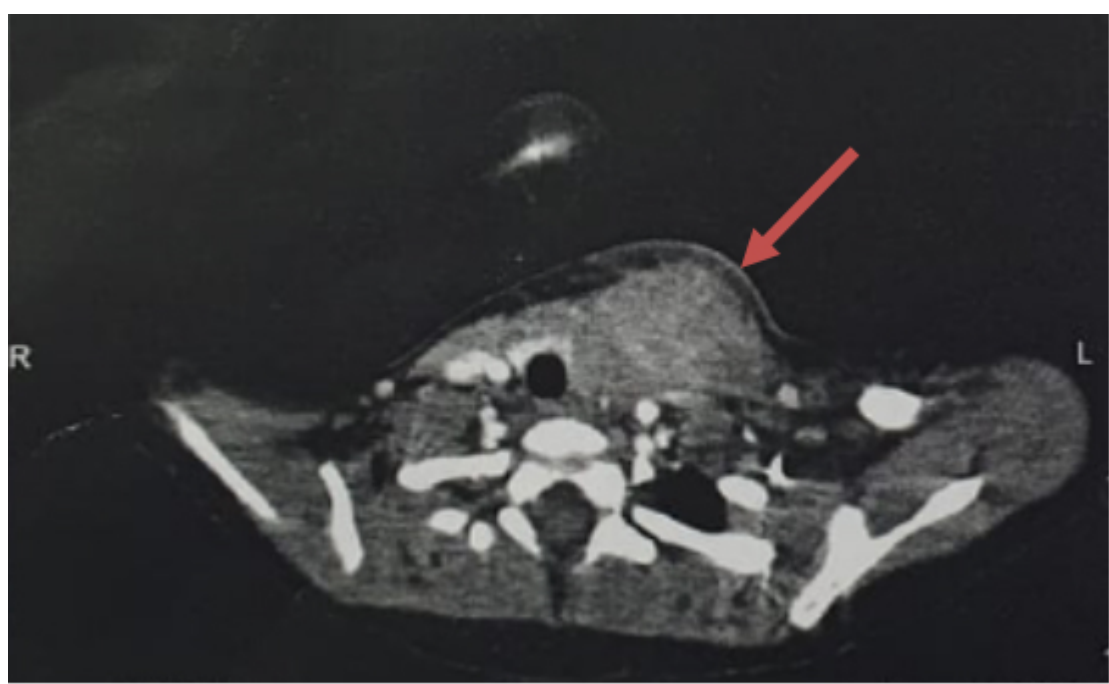

Se evidencia una masa con densidad de partes blandas en contacto con la glándula tiroides y en el espesor del músculo esternocleidomastoideo (flecha) de 3,5 cm de diámetro. Presenta un refuerzo heterogéneo luego de la administración de contraste por vía intravenosa, compatible con un absceso. 
Las manifestaciones clínicas típicas son la presencia de una tumoración dolorosa en la región anterior del cuello, que suele acompañarse de otros signos de flogosis como edema, eritema y aumento de la temperatura local. ${ }^{2}$ Otros signos y síntomas que acompañan el cuadro son la fiebre, la disfagia, linfadenopatías y malestar general. ${ }^{4}$ La presencia de sintomatología respiratoria debe alertar sobre una probable compresión de la vía aérea. El cuadro suele estar precedido por una infección de vía aérea superior, ${ }^{4}$ como ocurrió en la paciente aquí presentada, que luego evolucionó con la signo-sintomatología típica mencionada.

En relación con los exámenes complementarios, en el laboratorio es frecuente observar leucocitosis y aumento de la PCR y de la eritrosedimentación como reactantes de fase aguda. En cuanto al perfil tiroideo, más del $90 \%$ de los pacientes permanecen eutiroideos, como en este caso. ${ }^{4}$

Se recomienda realizar una biopsia con aguja fina para la tinción de Gram y cultivo con el fin de diagnóstico microbiológico. ${ }^{3}$ En el caso presentado, no fue posible realizarla porque la consistencia de la lesión no lo permitía y la paciente presentó una respuesta rápida y favorable ante la instauración del tratamiento antibiótico por vía IV.

Los estudios por imágenes más utilizados para el diagnóstico de la TAS son la ecografía y la TAC.

Los diagnósticos diferenciales que deben ser considerados son las infecciones, sobre todo la adenitis, y otros cuadros no infecciosos como las tiroiditis subagudas (de Quervain), hemorragias de nódulos preexistentes o procesos crónicos, incluidos los de naturaleza maligna., ${ }^{3,4}$

El tratamiento de la TAS se basa en la antibioticoterapia, que deberá instaurarse por vía IV hasta la resolución sintomática con disminución del tamaño de la tumoración. Los antibióticos utilizados deberán ser de amplio espectro; es decir, se deben escoger aquellos que, empíricamente, actúan contra patógenos más frecuentes en estas infecciones (aerobios y anaerobios). Luego se adecúa según la sensibilidad antimicrobiana si hubiera rescate en el cultivo. ${ }^{2,3}$ Algunas alternativas podrían ser el uso de clindamicina, como en el caso relatado, o el uso de betalactámicos, como amoxicilina/ ácido clavulánico, garantizando de esta manera la cobertura de las especies de Staphylococcus, Streptococcus y otras presentes en la flora orofaríngea. ${ }^{2,3}$ Se recomienda la realización de drenaje quirúrgico de las lesiones abscedadas. ${ }^{2}$

No se ha establecido el porcentaje de recurrencia en pacientes con tiroiditis aguda secundaria a fístula del seno piriforme, pero se presume que es elevado, por lo que se encuentra recomendada la resolución quirúrgica luego del primer episodio de infección. ${ }^{4}$

Las complicaciones de la TAS pueden ser infecciosas, como la mediastinitis; mecánicas, que causan obstrucción de la vía aérea y trombosis de estructuras vasculares; o endocrinas, como la tirotoxicosis transitoria $\mathrm{o}$, menos frecuentemente, el hipotiroidismo. ${ }^{2}$

En síntesis, si bien la infección de la glándula tiroides es una entidad rara durante la infancia, el alto índice de sospecha es fundamental para el diagnóstico debido a su prevalencia baja pero potencial gravedad. Por otro lado, debido a la gran asociación con anomalías congénitas, es imperioso descartar las mismas ante un primer episodio, y de este modo prevenir recurrencias.

\section{REFERENCIAS}

1. Paes JE, Burman KD, Cohen J, Franklyn J, et al. Acute bacterial suppurative thyroiditis: a clinical review and expert opinion. Thyroid. 2010; 20(3):247-55.

2. BrookI.Microbiology and managementofacutesuppurative thyroiditis in children. Int J Pediatr Otorhinolaryngol. 2003; 67(5):447-51.

3. Shah SS, Baum SG. Diagnosis and management of infectious thyroiditis. Curr Infect Dis Rep. 2000; 2(2):147-53.

4. Chirinos JL, Uzcategui L, Paoli M, Briceno Y. Tiroiditis aguda supurada: presentación de dos casos pediátricos. Rev Venez Endocrinol Metab. 2010; 8(3):108-15.

5. Barbero Alonso S, Ferrer García JC, Sánchez JC, Galbis Carvajal J, et al. Presentación atípica de tiroiditis aguda supurada en paciente inmunocompetente. Endocrinol Nutr. 2013; 60(4):211-3.

6. Cuestas G, Rodríguez V, Bellia Munzón P, Bellia Munzón G. Absceso retrofaríngeo por fístula congénita del seno piriforme en una adolescente. Arch Argent Pediatr. 2020; 118(1):e81-4. 